\title{
ANALISIS STUDI KELAYAKAN INDUSTRI GULA SEMUT (STUDI KASUS DI DESA KEBONREJO KECAMATAN CANDIMULYO KABUPATEN MAGELANG)
}

\author{
Analysis of Feasibility Study of the Brown Sugar Industry \\ (Case Study in Kebonrejo Village, Candimulyo District, Magelang District)
}

\author{
Marosimy Millaty ${ }^{1) *}$, Liana Fatma Leslie Pratiwi ${ }^{2)}$ \\ ${ }^{1)}$ Universitas Nahdlatul Ulama Yogyakarta \\ Jl. Lowanu No.47, Sorosutan, DI. Yogyakarta 55162, Indonesia \\ ${ }^{2}$ Universitas Pembangunan Nasional Veteran Yogyakarta \\ JL. SWK 104 Lingkar Utara, Conong Catur, Sleman, DI. Yogyakarta, Indonesia \\ *Email korespondensi : marosimy@unu-jogja.ac.id
}

Diterima tanggal : 15 Juni 2020 ; Disetujui tanggal 30 Juni 2020

\begin{abstract}
This study aims to identify the availability of production factors and to determine the feasibility of processing coconut palm juice into brown sugar in Kebonrejo Village, Candimulyo District, Magelang Regency. This research was conducted in Kebonrejo Village, with the consideration that Kebonrejo Village was the center of the brown sugar industry in Magelang Regency. The research sample was taken by simple random sampling (simple random sample) of 30 people. The analysis used in this study, using a descriptive method, by observing the extent of the availability of factors of production in the study area. The production factors observed in this study were mastery of coconut trees, raw materials, and labor. For feasibility analysis, BEP (Break Even Point) analysis of production, price $B E P$, and $R / C$ analysis are used. Based on the results of the study, it is known that the availability of production factors at the research location is well available, so this industry has prospects for development. In addition, it is known that the average brown sugar production at the study site is 7.89, greater than the production BEP of 2.23 (if implicit variable costs are not calculated) and 3.17 (if implicit variable costs are calculated). For BEP the price obtained is Rp. 2,406.13 per kg if implicit variable costs are taken into account and Rp. 6,655.22 per $\mathrm{kg}$ if implicit variable costs are not taken into account. BEP value is smaller than the selling price of brown sugar at the level of craftsmen which is Rp. $18,500.00$, meaning that this business is feasible to run. Based on $R / C$ analysis, it is known that the $R / C$ value is 7.69. $R / C$ value is greater than 1 , which means this business is feasible to run.
\end{abstract}

Keywords: breakeven point, brown sugar, feasibility, 
Jurnal Dinamika Sosial Ekonomi, 21 (1) : 92-104

\begin{abstract}
ABSTRAK
Penelitian ini bertujuan untuk mengidentifikasi ketersediaan faktor produksi dan untuk mengetahui kelayakan usaha pengolahan nira kelapa menjadi gula semut di Desa Kebonrejo Kecamatan Candimulyo Kabupaten Magelang. Penelitian ini dilakukan di Desa Kebonrejo, dengan pertimbangan bahwa Desa Kebonrejo merupakan sentra industri gula semut di Kabupaten Magelang. Sampel penelitian diambil secara simple random sampling (sampel acak sederhana) sebanyak 30 orang. Analisis yang digunakan pada penelitian ini, menggunakan metode deskriptif, dengan mengamati sejauh mana ketersediaan faktor produksi di daerah penelitian. Faktor produksi yang diamati pada penelitian ini yaitu penguasaan pohon kelapa, bahan baku, dan tenaga kerja. Untuk analisis kelayakan usaha, digunakan analisis BEP (Break Even Point) produksi, BEP harga, dan analisis $\mathrm{R} / \mathrm{C}$. Berdasarkan hasil penelitian, diketahui ketersediaan faktor produksi di lokasi penelitian tersedia dengan baik, sehingga industri ini memiliki prospek untuk dikembangkan. Selain itu, diketahui jika rata-rata produksi gula semut di lokasi penelitian sebesar 7,89, lebih tinggi dibandingkan BEP produksi sebesar 2,23 (jika biaya variabel implisit tidak dihitung) dan sebesar 3,17 (jika biaya variabel implisit ikut dihitung). Untuk BEP harga diperoleh hasil sebesar Rp 2.406,13 per $\mathrm{kg}$ jika biaya variabel implisit ikut diperhitungkan dan sebesar $\mathrm{Rp} 6.655,22 \mathrm{per} \mathrm{kg}$ jika biaya variabel implisit tidak ikut diperhitungkan. Nilai BEP harga lebih kecil dibandingkan harga jual gula semut di tingkat pengrajin yaitu sebesar Rp 18.500,00, artinya usaha ini layak untuk dijalankan. Berdasarkan analisis R/C diketahui jika nilai R/C sebesar 7,69. Nilai R/C lebih besar dari 1 yang berarti usaha ini layak untuk dijalankan.
\end{abstract}

Kata kunci: titik impas, gula semut, kelayakan

\title{
PENDAHULUAN
}

Masyarakat Indonesia dikenal memiliki keterampilan luar biasa di dalam mengolah sumberdaya alam menjadi produk dengan nilai jual lebih tinggi. Salah satu kelompok masyarakat yang jeli memanfaatkan kekayaan alamnya adalah masyarakat Desa Kebonrejo Kecamatan Candimulyo Kabupaten Magelang. Magelang merupakan salah satu sentra pohon kelapa di Jawa Tengah, dimana berdasarkan data dari (BPS Magelang, 2020), pada tahun 2018 terdapat seluas 7.830 hektar lahan yang sudah ditanami kelapa dan meningkat menjadi 7.860 hektar di tahun 2019.

Desa Kebonrejo yang secara geografis merupakan bagian dari wilayah Kabupaten Magelang, juga dianugerahi keberadaan pohon kelapa yang berlimpah. Oleh masyarakat setempat, pohon kelapa selain diambil buahnya untuk dijual, juga di-deres niranya untuk diolah lebih lanjut. Pengolahan nira menjadi produk 
Millaty \& Pratiwi., Analisis Studi Kelayakan Industri Gula Semut (Studi Kasus....

olahan penting dilakukan karena nira memiliki karakteristik cepat rusak. Menurut Irmawati et.al. (2015), produk pertanian yang mempunyai sifat mudah rusak dan tidak tahan lama, perlu dilakukan suatu proses pengolahan agar dapat meningkatkan nilai tambah melalui produk olahan dalam bentuk setengah jadi maupun barang jadi.

Industri rumah tangga di Desa Kebonrejo memanfaatkan nira yang terdapat di daerahnya tersebut, menjadi gula semut, dimana gula semut sendiri merupakan salah satu produk unggulan Indonesia. Gula semut berbentuk butiran halus berwarna cokelat. Hal inilah yang mendasari produk ini diberi nama gula semut, karena bentuknya yang seperti sarang semut. Perkembangan agroindustri gula semut tidak dapat dihindarkan lagi karena merupakan komoditas yang unggulan dan memberikan nilai tambah yang besar (Evalia, 2015).

Usaha pengolahan gula semut di Desa Kebonrejo, menjadi salah satu mata pencaharian utama, di mana masyarakat banyak yang menggantungkan hidupnya dari usaha ini. Menurut Supomo (2007), kehidupan pengrajin gula kelapa belum meningkat dari waktu ke waktu. Untuk itu, mengetahui kelayakan usaha menjadi hal yang manarik untuk diteliti, karena kelayakan usaha menjadi alasan utama bagi pelaku usaha untuk tetap fokus melanjutkan bisnis yang sedang digeluti, atau memilih untuk berbisnis usaha lain yang dirasa lebih menjanjikan. Penelitian ini bertujuan untuk mengidentifikasi ketersediaan faktor produksi di lokasi penelitian. Selain itu, penelitian ini juga bertujuan untuk mengetahui kelayakan usaha pengolahan nira kelapa menjadi gula semut di Desa Kebonrejo Kecamatan Candimulyo Kabupaten Magelang.

\section{METODE PENELITIAN}

\section{Metode Penentuan Daerah Penelitian dan Sampel Penelitian}

Penelitian ini dilakukan di Desa Kebonrejo Kecamatan Candimulyo Kabupaten Magelang. Penunjukan Desa Kebonrejo sebagai lokasi penelitian dilakukan secara sengaja (purposive) dengan pertimbangan bahwa Desa Kebonrejo merupakan sentra industri gula semut di Kabupaten Magelang. Sampel penelitian diambil secara simple random sampling (sampel acak sederhana) 
Jurnal Dinamika Sosial Ekonomi, 21 (1) : 92-104

sebanyak 30 orang sampel. Menurut Agung (2006) di dalam Alwi, (2012), ukuran sampel minimal adalah sebesar 30, dimana ukuran sampel ini telah dapat dipakai untuk mendekati distribusi binomial.

\section{Metode Analisis Data}

Analisis yang digunakan pada penelitian ini, menggunakan metode deskriptif, dengan mengamati sejauh mana ketersediaan faktor produksi di daerah penelitian. Faktor produksi yang diamati pada penelitian ini yaitu penguasaan pohon kelapa, bahan baku, dan tenaga kerja. Untuk analisis kelayakan usaha, digunakan analisis BEP (Break Even Point) dan analisis R/C. Analisis R/C ratio memiliki kriteria (Soekartawi, 2006) :

Jika R/C > 1, maka usaha layak untuk dilaksanakan

Jika $\mathrm{R} / \mathrm{C}=1$, maka usaha impas

Jika $\mathrm{R} / \mathrm{C}<1$, maka usaha tidak layak untuk dilaksanakan

Untuk analisis BEP, digunakan analisis BEP produksi dan BEP harga.

$$
\begin{aligned}
& \mathrm{BEP} \text { produksi }=\mathrm{XBEP}=(\mathrm{TFC} / \mathrm{P}-\mathrm{AVC}) \times 1 \mathrm{~kg} \\
& \mathrm{BEP} \text { Harga }=\mathrm{TC} / \mathrm{Y}
\end{aligned}
$$

Keterangan:

TFC = Biaya tetap total

AVC = Rata-rata biaya variabel per satuan

$\mathrm{P} \quad=$ Harga jual per unit

$\mathrm{Y} \quad=$ Produksi

Total Cost (TC) adalah seluruh biaya yang dikeluarkan oleh pengrajin gula semut, terdiri dari biaya tetap dan biaya variabel, dirumuskan sebagai berikut:

$$
\mathrm{TC}=\mathrm{FC}+\mathrm{VC}
$$

Keterangan:

$\mathrm{TC}=$ Biaya total

$\mathrm{FC}=$ Biaya tetap

$\mathrm{VC}=$ Biaya variabel 
Millaty \& Pratiwi., Analisis Studi Kelayakan Industri Gula Semut (Studi Kasus....

Total Revenue (TR) adalah total penerimaan pengrajin gula semut dari produksi yang dikalikan dengan harga jual, dapat diformulasikan sebagai berikut:

$$
\mathrm{TR}=\mathrm{Pq} \times \mathrm{Q}
$$

Keterangan:

TR $=$ Pendapatan kotor $(\mathrm{Rp})$

$\mathrm{Q} \quad=$ Produksi gula semut $(\mathrm{kg})$

$\mathrm{Pq}=$ Harga gula semut yang diterima pengrajin $(\mathrm{Rp} / \mathrm{kg})$

\section{HASIL DAN PEMBAHASAN}

\section{Ketersediaan Faktor Produksi}

\section{Faktor Produksi Penguasaan Pohon Kelapa}

Untuk meningkatkan penerimaan dari usaha pengolahan gula kelapa, pengrajin perlu mengoptimalkan produksinya, yaitu dengan jalan menambah biaya produksi seperti menambah bahan baku utama, yaitu air nira (Mugiono et.al., 2014). Banyak sedikitnya air nira diperoleh dari penguasaan pohon kelapa. Hal ini membuat penguasaan pohon kelapa menjadi salah satu faktor produksi yang penting di dalam pembuatan gula semut ini.

Tabel 1. Penguasaan Pohon Kelapa Pengrajin Gula Semut yang Menjadi Responden

\begin{tabular}{crr}
\hline Kepemilikan Pohon Kelapa (Pohon) & Jumlah (Orang) & Persentase (\%) \\
\hline $1-5$ & 10 & 33,33 \\
$6-10$ & 14 & 46,67 \\
$11-15$ & 4 & 13,33 \\
$16-20$ & 1 & 3,33 \\
$21-25$ & 0 & 0,00 \\
$26-30$ & 1 & 3,33 \\
Total & 30 & 100,00 \\
\hline
\end{tabular}

Sumber: Data Primer (2019)

Penguasaan pohon kelapa para responden penelitian yaitu milik sendiri dan maro. Maro adalah istilah lokal untuk menyebut istilah menyewakan pohon kelapa kepada orang lain untuk di-deres. Sewa menyewa ini pohon kelapa untuk di-deres atau disadap sari bunga kelapanya yang nantinya akan diolah menjadi gula, dengan metode pembayaran biaya sewanya menggunakan gula hasil dari pemanfaatan pohon kelapa tersebut (Hafidin, 2019). Berdasarkan tabel 1, terlihat 
Jurnal Dinamika Sosial Ekonomi, 21 (1) : 92-104

bahwa responden paling banyak memiliki pohon kelapa brownara 6 sampai 10 pohon sebanyak 14 responden. Status kepemilikan pohon ini, akan mempengaruhi produksi gula semut. Semakin banyak memiliki pohon kelapa yang di-deres maka akan semakin banyak gula semut yang dihasilkan.

\section{Faktor Produksi Bahan Baku}

Bahan baku utama pembuatan gula semut, yaitu nira kelapa, tersedia dalam jumlah yang berbeda-beda bagi para responden. Hal ini dipengaruhi oleh penguasaan pohon kelapa. Selain itu, menurut Aristya, et.al. (2013) jumlah perolehan nira setiap pohon kelapa dipengaruhi keterampilan menyadap dan juga umur tanaman. Pohon kelapa yang lebih muda akan menghasilkan jumlah nira yang lebih tinggi dibandingkan dari hasil tanaman yang telah tua. Jumlah produksi nila kelapa yang rendah disebabkan karena karakteristik pertumbuhan kelapa kurang mampu menghasilkan asimilat besar dan rendemen gula, hal ini dipengaruhi oleh penanganan nira saat di panen sampai dimasak menjadi gula (Mashud \& Matana, 2014).

Setiap pohon kelapa, di-deres setiap pagi dan sore hari, dengan rata-rata hasil sadapan nira sebanyak 4 liter per pohon per hari. Untuk menghasilkan $1 \mathrm{~kg}$ gula semut, diperlukan nira sebanyak 3 liter. Sumber bahan baku ini, cukup tersedia melimpah di lokasi penelitian. Hal ini disebabkan gula semut menjadi salah satu produk unggulan daerah melalui program One Village One Product (OVOP) (RKPD Kabupaten Magelang 2016 cit. (Purnomo et.al., 2018).

\section{Faktor Produksi Tenaga Kerja}

Industri gula semut merupakan industri rumah tangga, yang mana pengrajinnya mayoritas merupakan ibu rumah tangga. Melihat hal ini, bisa dikatakan jika ketersediaan tenaga kerja pada industri gula semut di Desa Kebonrejo, tidak sulit untuk didapatkan, karena menjadi profesi utama mayoritas ibu rumah tangga setempat. Berdasarkan angkatan kerjanya, tenaga kerja gula semut di Desa Kebonrejo dibagi menjadi angkatan kerja muda (17-25 tahun), angkatan kerja produktif (26-55 tahun) dan angkatan kerja tua (59-70 tahun). 
Millaty \& Pratiwi., Analisis Studi Kelayakan Industri Gula Semut (Studi Kasus....

Tabel 2. Kelompok Usia Pengrajin Gula Semut yang Menjadi Responden

\begin{tabular}{ccc}
\hline Usia (Tahun) & Jumlah (Orang) & Persentase $(\%)$ \\
\hline $17-25$ & 0 & 0,00 \\
$26-55$ & 25 & 83,33 \\
$56-70$ & 5 & 16,67 \\
Total & 30 & 100,00 \\
\hline
\end{tabular}

Sumber: Data Primer (2019)

Tabel 2, menunjukkan usia pengrajin gula semut di lokasi penelitian. Berdasarkan tabel 2, diketahui jika mayoritas tenaga kerja pembuat gula semut didominasi oleh tenaga kerja produktif sebesar $83,33 \%$. Pengrajin yang berusia tidak produktif melakukan aktivitas sebagai pengrajin gula semut karena pekerjaan ini sudah dilakukan dari usia muda/ produktif.

\section{Analisis Kelayakan Usaha Pembuatan Gula Semut di Desa Kebonrejo} Kecamatan Candimulyo Kabupaten Magelang

\section{Biaya Tetap (Fix Cost)}

Biaya tetap adalah biaya yang dikeluarkan oleh produsen dengan tidak memperhatikan besarnya barang atau jasa yang diproduksi. Untuk industri gula semut di Desa Kebonrejo, biaya tetap yang digunakan yaitu penyusutan peralatan yang digunakan untuk men-deres nira dan peralatan yang digunakan untuk memasak gula semut. Peralatan yang masuk dalam komponen biaya tetap yaitu arit, bambu, kompor, wajan, pengaduk, saringan kecil, penggerus/batok kelapa, nampan, dan pengayak. Tabel 3 menunjukkan rata-rata total biaya tetap untuk memproduksi gula semut.

Tabel 3. Rata-rata Total Biaya Tetap per Bulan

\begin{tabular}{lrr}
\hline \multicolumn{1}{c}{ Komponen Biaya } & Total Biaya (Rp) & Persentase (\%) \\
\hline Penyusutan alat untuk deres & $11.844,91$ & 32,39 \\
Penyusutan alat untuk membuat gula semut & $24.727,31$ & 67,61 \\
\hline Total & $36.572,22$ & 100,00 \\
\hline
\end{tabular}

Sumber: Data Primer, 2019 (diolah)

Biaya tetap yang dikeluarkan untuk membuat gula semut lebih besar dibandingkan untuk men-deres, hal ini dikarenakan peralatan untuk men-deres masih sederhana. Penyadapan nira tanaman kelapa masih dilakukan secara 
Jurnal Dinamika Sosial Ekonomi, 21 (1) : 92-104

tradisional. Tukang sadap memanjat pohon kelapa, mengiris mayang muda, dan menampung nira dengan wadah dari bambu (Tamrin, 2013).

\section{Biaya Variabel (Variable Cost)}

Biaya variabel adalah biaya yang berubah mengikuti jumlah produksi barang atau jasa (Pratiwi et.al., 2020). Pada penelitian ini, biaya variabel yang digunakan adalah biaya variabel eksplisit (bahan bakar, bahan penolong, sewa pohon, pupuk) dan biaya variabel implisit (tenaga kerja men-deres dan tenaga kerja membuat gula semut). Tabel 4 menunjukkan rata-rata total biaya variabel untuk memproduksi gula semut.

Tabel 4. Rata-rata Total Biaya Variabel per Bulan

\begin{tabular}{|c|c|c|}
\hline Komponen Biaya & $\begin{array}{c}\text { Total Biaya } \\
\text { (Rp) }\end{array}$ & Persentase $(\%)$ \\
\hline \multicolumn{3}{|l|}{ Biaya eksplisit: } \\
\hline Bahan bakar & $257.713,79$ & 16,63 \\
\hline Bahan penolong & $7.604,76$ & 0,49 \\
\hline Sewa pohon & $7.400,00$ & 0,48 \\
\hline Pupuk & $260.000,00$ & 16,78 \\
\hline \multicolumn{3}{|l|}{ Biaya implisit: } \\
\hline Tenaga kerja men-deres & $491.428,57$ & 31,72 \\
\hline Tenaga kerja membuat gula semut & $525.333,33$ & 33,90 \\
\hline Total & $1.549 .480,46$ & 100,00 \\
\hline
\end{tabular}

Sumber: Data Primer, 2019 (diolah)

Berdasarkan tabel 4, diketahui jika alokasi biaya variabel yang paling besar dikeluarkan oleh pengrajin gula semut adalah biaya tenaga kerja, baik biaya tenaga kerja menderes maupun biaya tenaga kerja membuat gula semut dengan persentase $31,71 \%$ dan $33,90 \%$. Akan tetapi, biaya tenaga kerja ini, tidak begitu dirasakan dampaknya oleh para pengrajin gula semut di Desa Kebonrejo, karena biaya tenaga kerja merupakan biaya implisit (biaya tidak terlihat) atau biaya yang tidak diperhitungkan oleh para pengrajin gula semut. Tenaga kerja merupakan biaya implisit karena tenaga kerja yang digunakan dalam kegiatan produksi gula semut merupakan tenaga kerja keluarga. Pengrajin biasanya memberdayakan anggota keluarganya untuk membantu kegiatan produksi gula semut. 
Millaty \& Pratiwi., Analisis Studi Kelayakan Industri Gula Semut (Studi Kasus....

\section{Analisis Kelayakan Usaha}

\section{Break Even Point (BEP) Produksi}

Analisis BEP produksi gula semut dilakukan untuk mengetahui pada jumlah produksi berapa pengrajin mengalami titik impas.

Rumus BEP produksi:

$$
\mathrm{XBEP}=\mathrm{TFC} / \mathrm{P}-\mathrm{AVC} \times 1 \mathrm{~kg}
$$

Jika rata-rata biaya variabel implisit tidak dimasukkan dalam perhitungan BEP produksi, diperoleh:

BEP produksi $=(36.572,22 /(18.500,00-2.089,94)) \times 1 \mathrm{~kg}=2,23 \mathrm{~kg}$

Jika rata-rata biaya variabel implisit ikut dimasukkan dalam perhitungan BEP produksi, diperoleh:

BEP produksi $=(36.572,22 /(18.500,00-6.972,76)) \times 1 \mathrm{~kg}=3,17 \mathrm{~kg}$

Berdasarkan hasil perhitungan, BEP produksi gula semut di lokasi penelitian jika dihitung dengan tidak memasukkan biaya variabel implisit yaitu sebesar 2,23 kg setiap produksi. Sedangkan BEP produksi gula semut jika dihitung dengan memasukkan nilai biaya variabel implisit yaitu sebesar 3,17 kg setiap produksi. BEP produksi yang dihitung, baik menggunakan biaya variabel implisit maupun tidak menggunakan biaya variabel implisit, masih lebih rendah dari rata-rata produksi pengrajin gula semut di Desa Kebonrejo, dimana berdasarkan hasil penelitian rata-rata produksi gula semut responden penelitian yaitu sebesar 7,89 kg. Sehingga dapat disimpulkan jika usaha industri gula semut ini layak untuk dijalankan.

\section{Break Even Point (BEP) Harga}

Analisis BEP harga untuk mengetahui apakah harga jual produk sudah layak, dalam artian pengrajin tidak mengalami kerugian. Hasil dari perhitungan BEP harga ini, akan menjadi harga keseimbangan, yang berarti pada harga tersebut pengrajin gula semut tidak mengalami untung dan juga rugi (impas). BEP harga pengrajin gula semut di Desa Kebonrejo sebagai berikut: 
Jurnal Dinamika Sosial Ekonomi, 21 (1) : 92-104

Rumus BEP harga (Rp):

$$
\mathrm{XBEP}=\mathrm{TC} / \mathrm{Y}
$$

Jika total biaya variabel implisit tidak dimasukkan dalam perhitungan BEP harga, diperoleh:

$\mathrm{BEP}$ harga $=569.290,78 / 236,60=\mathrm{Rp} 2.406,13$

Jika total biaya variabel implisit ikut dimasukkan dalam perhitungan BEP harga, diperoleh:

$\mathrm{BEP}$ harga $=1.574 .624,11 / 236,60=\operatorname{Rp} 6.655,22$

Diketahui harga gula semut per kg di Desa Kebonrejo yaitu sebesar Rp 18.500,00. Sebesar Rp 500 disimpan dalam kas kelompok, sehingga nominal yang diterima pengrajin yakni sebesar Rp 18.000,00. Sehingga industri gula semut di lokasi penelitian layak untuk dijalankan karena harga jual produk di atas harga BEPnya.

\section{Analisis $R / C$}

$\mathrm{R} / \mathrm{C}$ rasio merupakan analisis yang digunakan untuk mengukur kelayakan usaha dengan menggunakan perbandingan penerimaan (revenue) dan biaya (cost). Pada penelitian ini, total biaya yang digunakan untuk menghitung analisis $\mathrm{R} / \mathrm{C}$ adalah total biaya yang berasal dari biaya tetap dan biaya variabel eksplisit. Untuk biaya variabel implisit, tidak termasuk dalam komponen biaya analisis R/C. Tabel 5 menunjukkan perhitungan analisis R/C.

Tabel 5. Tabel Perhitungan Analisis R/C

\begin{tabular}{lr}
\hline \multicolumn{1}{c}{ Keterangan } & Nilai \\
\hline Total Revenue & $4.377 .100,00$ \\
TFC & $36.572,22$ \\
TVCeksplisit & $532.718,55$ \\
Total Biaya (TFC + TVCeksplisit) & $569.289,77$ \\
R/C & 7,69 \\
\hline
\end{tabular}

Sumber: Data Primer, 2019 (diolah)

Berdasarkan tabel 5, diketahui jika nilai R/C pada industri gula semut di Desa Kebonrejo sebesar 7,69. Usaha ini layak untuk dijalankan, karena setiap Rp 
Millaty \& Pratiwi., Analisis Studi Kelayakan Industri Gula Semut (Studi Kasus....

1,00 yang dikeluarkan oleh pengrajin gula semut akan menerima pengembalian sebesar Rp 7,69. Kelayakan industri gula semut ini lebih besar dibandingkan gula aren yang memiliki nilai rasio $\mathrm{R} / \mathrm{C}$ yaitu sebesar 1,56 pada musim hujan dan 1,65 pada musim kemarau (Sukiyono et.al., 2012) juga lebih besar dibandingkan nilai kelayakan gula merah kelapa yang nilai B/C nya sebesar 1,12 (Mustaqim, 2019). Apabila dianalisis lebih lanjut, dari 30 responden gula semut yang dijadikan sampel penelitian, dapat dibagi menjadi 3 kelompok yang dapat dilihat pada tabel 6.

Tabel 6. Tabel Pengelompokan Nilai R/C

\begin{tabular}{lrr}
\hline Nilai R/C & Responden (orang) & Persentase (\%) \\
\hline $0-5,00$ & 8 & 26,67 \\
$5,01-10,00$ & 21 & 70,00 \\
10,00 & 1 & 3,33 \\
\hline Total & 30 & 100,00 \\
\hline
\end{tabular}

Sumber: Data Primer, 2019 (diolah)

Berdasarkan tabel 6, dapat dilihat bahwa responden yang memiliki nilai R/C brownara 5,01 sampai 10,00 adalah yang paling banyak, yaitu sebesar 21 responden dengan rata-rata nilai $\mathrm{R} / \mathrm{C}$ sebesar 7,45. Artinya, setiap $\mathrm{Rp} 1$ yang dikeluarkan akan memberikan pengembalian sebesar $\mathrm{Rp}$ 7,45. Sedangkan responden yang memiliki nilai $\mathrm{R} / \mathrm{C}$ kurang dari 5,00 h6anya satu orang, dimana nilai $\mathrm{R} / \mathrm{C}$ nya sebesar 4,60 yang berarti setiap Rp 1 yang dikeluarkan akan memberikan pengembalian sebesar Rp 4,60. Hal ini dapat disimpulkan bahwa usaha memproduksi gula semut merupakan usaha yang menguntungkan dan layak untuk dikembangkan.

\section{KESIMPULAN DAN SARAN}

\section{Kesimpulan}

Produksi gula semut di Desa Semedo Kecamatan Candimulyo Kabupaten Magelang merupakan indutri rumah tangga yang layak untuk dijalankan. Jika dilihat dari segi ketersedian faktor produksi, keberadaan factor produksi di lokasi penelitian yang terdiri dari penguasaan pohon kelapa, bahan baku, dan tenaga 
Jurnal Dinamika Sosial Ekonomi, 21 (1) : 92-104

kerja tersedia dengan baik. Berdasarkan perhitungan BEP produksi dan BEP harga, diketahui jika usaha ini layak untuk dijalankan karena nilai BEP produksinya lebih kecil dibandingkan rata-rata produksi harian pengrajin gula semut. Begitu pula dengan BEP harga yang lebih kecil dibandinkan harga jual gula semut. Berdasarkan analisis R/C diketahui jika nilai R/C sebesar 7,69. Nilai $\mathrm{R} / \mathrm{C}$ lebih besar dari 1 yang berarti usaha ini layak untuk dijalankan.

\section{Saran}

Perlu inovasi bagi kelompok pengrajin gula semut di lokasi penelian agar memproduksi gula semut dalam bentuk kemasan yang lebih kecil. Hal ini agar penjualan gula semut dapat langsung menembus pasar perhotelan dan swalayan sehingga pangsa pasarnya bisa lebih luas.

\section{DAFTAR PUSTAKA}

Alwi, I. (2012). Kriteria Empirik dalam Menentukan Ukuran Sampel Pada Pengujian Hipotesis Statistika dan Analisis Butir. Jurnal Formatif, 2(2), 140-148. https://doi.org/10.30998/formatif.v2i2.95

Aristya, V. E., Prajitno, D., Supriyanta, \& Taryono. (2013). Kajian Aspek Budidaya dan Identifikasi Keragaman Morfologi Tanaman Kelapa (Cocos Nucifera L.) di Kabupaten Kebumen. VEGETALIKA, 2(1), 101-115.

BPS Magelang, B. P. S. K. M. (2020). Kabupaten Magelang dalam Angka 2020. Magelang: Badan Pusat Statistik Kabupaten Magelang.

Evalia, N. A. (2015). Strategi Pengembangan Agroindustri Gula Semut Aren. Jurnal Manajemen Dan Agribisnis, 12(1), 57-67. https://doi.org/10.17358/jma.12.1.57

Hafidin, A. (2019). Akad Sewa Menyewa Pohon Kelapa Deresan Dalam Perspektif Hukum Islam (Studi Kasus Di Dusun Planjan Desa Langkap Kecamatan Bumiayu Kabupaten Brebes) (Institut Agama Islam Negeri Salatiga). Retrieved from http://erepository.perpus.iainsalatiga.ac.id/id/eprint/7464

Irmawati, I., Syam, H., \& Jamaluddin P, J. P. (2015). Analisis Kelayakan Finansial Dan Strategi Pengembangan Usaha Industri Rumahan Gula Semut (Palm Sugar) Dari Nira Nipah Di Kelurahan Pallantikang. Jurnal Pendidikan Teknologi Pertanian, 1(1), 76-94. https://doi.org/10.26858/jptp.v1i1.5147

Mashud, N., \& Matana, Y. R. (2014). Produktivitas Nira Beberapa Aksesi Kelapa Genjah. Buletin Palma, 15(2), 110-114. https://doi.org/10.21082/bp.v15n2.2014.110-114

Mugiono, Marwanti, S., \& Awami, S. N. (2014). Analisis Pendapatan Usaha Gula 
Millaty \& Pratiwi., Analisis Studi Kelayakan Industri Gula Semut (Studi Kasus....

Merah Kelapa (Studi kasus Di Desa Medono Kecamatan Kaliwiro kabupaten Wonosobo). Mediagro, 10(2), 22-31.

Mustaqim. (2019). Analisis Kelayakan Usaha Gula Merah Kelapa (Studi Kasus: Desa Tumpeng Kecamatan Candipuro Kabupaten Lumajang). Jurnal Inkofar, 1(1), 88-93.

Pratiwi, L. F. L., Rosyid, A. H. Al, \& Kafiya, M. (2020). Manajemen Usahatani. Yogyakarta: Lintang Pustaka Utama.

Purnomo, B. C., Murniningsih, R., \& Munahar, S. (2018). Pengembangan Usaha Gula Semut Sebagai Produk Unggulan Kabupaten Magelang Melalui Perluasan Pasar. The 8 Th University Research Colloquium 2018 Universitas Muhammadiyah Purwokerto, 181-186. Purwokerto: Universitas Muhammadiyah Purwokerto.

Soekartawi. (2006). Analisis Usaha Tani. Jakarta: UI Press.

Sukiyono, K., Nusril, Sumantri, B., \& Silvia, E. (2012). Analisa Efisiensi, Titik Impas, dan resiko usaha Kecil Gula Aren Di Kabupaten Rejang Lebong. Seminar Nasional Dan Rapat Tahunan Bidang Ilmu-Ilmu Pertanian BKSPTN Wilayah Barat, 453-459. Bengkulu: Universitas Bengkulu.

Supomo. (2007). Meningkatkan Kesejahteraan Pengrajin Gula Kelapa Di Wilayah Kabupaten Purbalingga. Jurnal Ekonomi Pembangunan, 12(2), 149-162.

Tamrin, T. (2013). Modifikasi Dan Perbaikan Kinerja Alat Pengiris Mayang Kelapa Untuk Menyadap Nira. Agritech, 33(4), 477-482. 